\title{
The Influences of Extrusion-Shear Process on Microstructures Evolution and Mechanical Properties of AZ31 Magnesium Alloy
}

\author{
Hongjun $\mathrm{Hu}^{\mathrm{a}, c_{*} *}$, Yang $\mathrm{Liu}^{\mathrm{b}, *}$, Dingfei Zhang ${ }^{\mathrm{a}}$, Zhongwen $\mathrm{Ou}^{\mathrm{c}}$ \\ ${ }^{a}$ Chongqing University of Technology, Chongqing, 400050, China \\ ${ }^{\mathrm{b}}$ Class F1302012, School of Mechanical Engineering,Shanghai Jiao Tong University, \\ Shanghai, 200240, China
}

${ }^{\mathrm{c}}$ Sichuan University of Science \& Engineering, 643000, China

* Corresponding authors. E-mail addresses: hhj@cqut.edu.cn (H.J. Hu), LY984648804@sjtu.edu.cn(Y. Liu)

\begin{abstract}
Severe plastic deformation(SPD) technologies are difficult to be promoted to be industrialized, and the processes are complicated, and the costs are high. To promote industrial application of the SPD technology for magnesium alloy, a new successive SPD method has been explored which includes direct extrusion and two steps equal channel angular extrusion (ECAE) continuously.The processing technology is called extrusion-shear (ES) in this paper. The components of ES dies have been designed, manufactured and installed on extruder to manufacture the AZ31 magnesium alloy rods. Microstructures of AZ31 magnesium alloy processed by ES process have been observed and investigated. The texture evolution during ES process has also been studied. The results show that fine and uniform microstructures can be obtained by ES process. Basal texture (0002) has been weakened owing to shear deformation of ES process. Research results show that relationship
\end{abstract}


between grain sizes and hardnesses is consistent with hall-petch law at $420{ }^{\circ} \mathrm{C}$ ES process with low billet temperature could improve hardness obviously and enhance compression performance,and raise strengths. And there exits strong tension-compression asymmetry of AZ31 magnesium alloy fabricated by ES process. The results indicate that ES process can produce large plastic deformation and introduce ultra-fined grains in the AZ31 magnesium alloy.

Key words : Magnesium alloy,Microstructure,Texture,

Extrusion-shear,Hardness

\section{Introduction}

As the lightest structural material of engineering significance, Magnesium alloys have been attracted considerable attentions[1-3]. However, Magnesium alloys exhibit poor formability and possess only moderate strength by comparing with aluminum alloys.One of the promising methods for increasing ductility and strength is microstructure refinements. Fine-grained materials is harder and stronger than those are coarsen because greater total grain boundaries can impede dislocation motions.Bulk nanostructure materials processed by SPD have attracted more interest of researchers.SPD have been used to fabricate ultrafine-grained materials with excellent mechanical properties and service performances generally. Currently, the SPD techniques have been developed such as equal channel angular extrusion(ECAE), accumulative roll-bonding process[4] and differential speed rolling[5].Among these methods,ECAE process is the most promising SPD technology and it has attracted a lot of research interest.The authors conducted the extrusion of AZ31 
magnesium $(\mathrm{Mg})$ alloy and refined the grains from $75 \mu \mathrm{m}$ to $2.5 \mu \mathrm{m}$ at $473 \mathrm{~K}$, and then to $0.1 \mu \mathrm{m}$ by eight passes of ECAE at $373 \mathrm{~K}[6]$. The extrusion plus ECAE (EX-ECAE) usually included more than 2 steps to obtain the fine grains, and the material may be oxidized. In addition, the application of ECAE process is only limited to the laboratory scale processing.The paper written by Dmitry Orlov et al. demonstrated the feasibility of SPD techniques which combine direct extrusion and ECAE in a single process[7], and processed material exhibits an excellent balance of strength and tensile ductility.

In the current research, a compound extrusion process has been explored to fabricate rods which included direct extrusion and two steps ECAE, and the processing technology is called extrusion-shear (ES) in this paper. The components of ES process die have been designed and manufactured and installed in a horizontal extruder.Microstructures of AZ31 alloy sampled from centers of longitudinal sections for different positions in prepared rods have been observed. Deformed microstructures and texture evolution of ES process for AZ31 magnesium alloy have been studied in order to analyze the deformation mechanisms. The aim of the present study is to reveal the microstructural evolution and clarify grain refinements mechanism for AZ31 magnesium alloy during ES process. Hardnesses distribution and tension-compression asymmetry of AZ31 alloy are measured experimentally through a series of tension and compression tests.

\section{Experimental procedures}

A schematic diagram of ES process is shown in Fig.1. which shows the 
configuration of designed and manufactured ES die. The diameter of rods extruded by the ES process is $15 \mathrm{~mm}$. The ES die includes direct extrusion with extrusion ratio of 32 and die channel angles of $120^{\circ}$. A larger amount of shear deformation in materials can be introduced by ES process than those caused by direct extrusion with the same ratio. There are four deformation zones in ES die. The deformation zone I and II is the direct extrusion zone which includes upsetting zone and sizing zone, and zone III and zone IV are the first and second shearing zones, respectively. Experiments have been done on a horizontal extrusion machine with extrusion ability 500 tons and a container diameter of $85 \mathrm{~mm}$. The material used in this study is AZ31 magnesium alloy. As-cast billets have been machined into round billet with diameter of $80 \mathrm{~mm}$. The process parameters of ES process, which are critical to the microstructure refinements and mechanical properties[8-9] have been listed in Table 1.

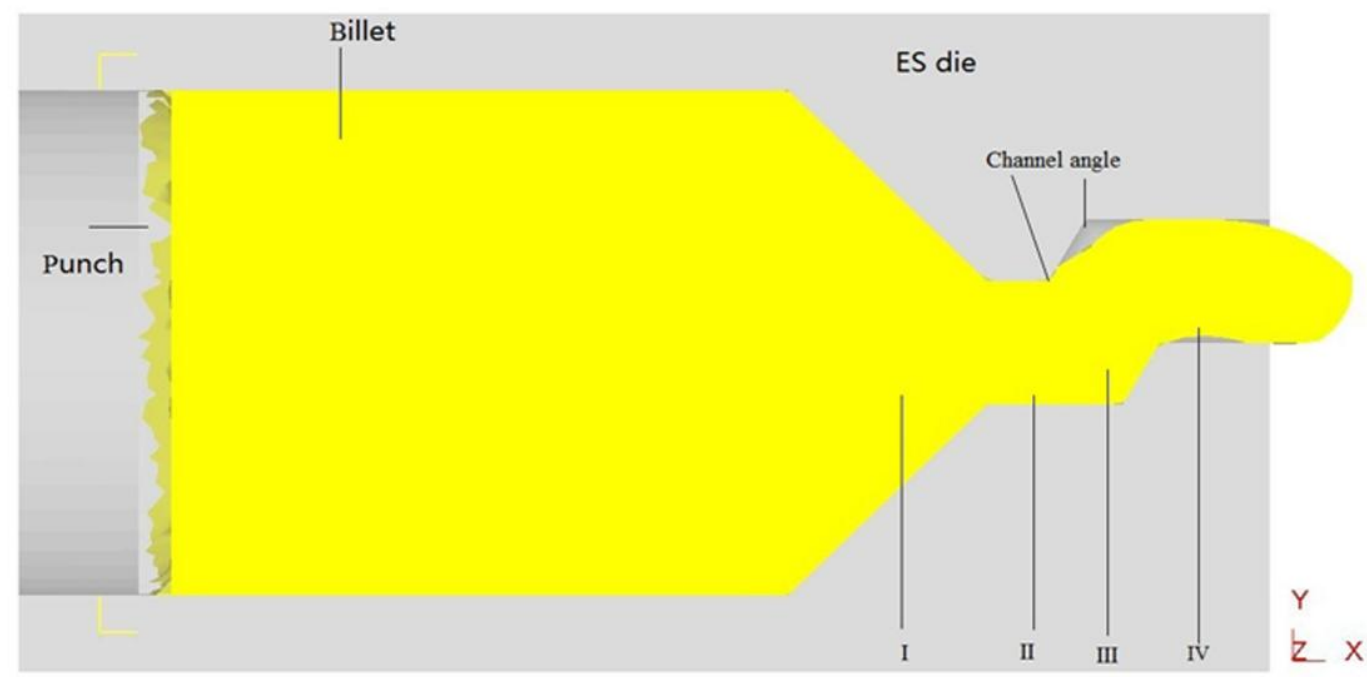

Fig.1. Schematic diagram of ES die with channel angle $120^{\circ}$ and some parts chosen to be researched:I-upsetting zone, II- sizing zone, III-the first shearing zone, IV-the second shearing zone. 
Table 1 Process parameters of ES process.

\begin{tabular}{llll}
\hline billet & die & container & extrusion \\
temperature & temperature & temperature & speed \\
\hline $420^{\circ} \mathrm{C}$ & $400^{\circ} \mathrm{C}$ & $400^{\circ} \mathrm{C}$ & $0.5 \mathrm{~m} / \mathrm{min}$ \\
$450^{\circ} \mathrm{C}$ & $430^{\circ} \mathrm{C}$ & $430^{\circ} \mathrm{C}$ & $0.5 \mathrm{~m} / \mathrm{min}$ \\
\hline
\end{tabular}

In this study, The billets and ES die have been heated up to a certain temperature and insulated to preserve heat, and then ES process started immediately. In the ES process experiments, oildag has been applied on the surface of workpieces and dies. Prepared samples have been taken from the four parts (shown in Fig.1) to investigate the microstructures and mechanical properties. All the samples have been taken from the center of longitudinal sections of different positions. The samples have been prepared for microstructural observations by using standard metallographic procedures including mounting, grinding and polishing. Then polished specimens are etched with an acetic acid. Acetic acid and picric acid solution $(2 \mathrm{ml}$ acetic acid $+1 \mathrm{~g}$ picric acid $+5 \mathrm{ml}$ water $+20 \mathrm{ml}$ of alcohol) have been used to erosion surface of the samples for microstructure observation.

Microstructure observations have been carried out by using PME OLYMPUS TOKYO-type optical microscope.The qualitative analyses of macro-texture have been achieved by using X-ray diffraction (XRD), while the micro-texture analysis for the direct extrusion zone and the second shearing 
zone have been examined by electron backscatter diffraction (EBSD).

Microstructure observations were realized by means of a transmission electron microscope (TEM) instrument.The hardness tests have been carried out on HV-1000 type microhardness tester, and applied load was 50g, and loading time was 20s, and average hardness of 25 points on each researched parts have been calculated.

Standard compression and tensile sample of $\varphi 8 \times 16 \mathrm{~mm}$ and $\delta 5$ tensile samples have been prepared. The mechanical properties of samples have been carried out in electronic universal testing machine CMT5150, and compression and tensile failure test have been done with $1 \mathrm{~mm} / \mathrm{min}$ speed.

\section{Results and discussions}

\subsection{Microstructures and texture evolution during ES process}

Fig.2 shows the original microstructures of AZ31 magnesium alloy with as-cast state,which consists of coarse grains and the second phase. The average grain size of the as-cast billet is estimated to be more than $200 \mu \mathrm{m}$, intermetallics either distribute around grain boundaries or in grain interior.

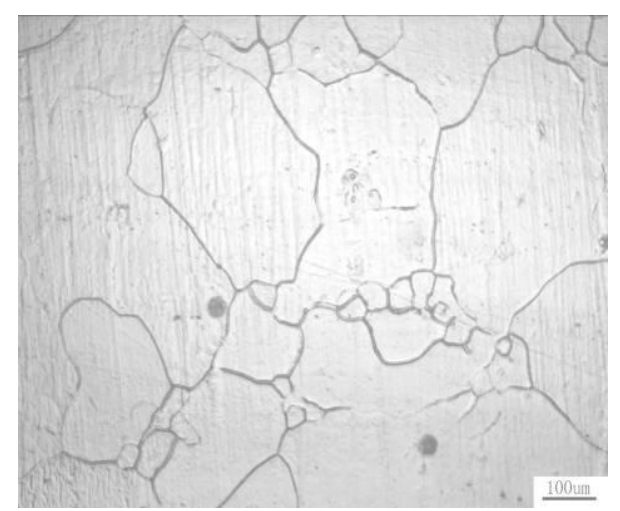

Fig.2. The original microstructures for as cast AZ31 magnesium alloy. 
Microstructures of the four zones in ES-processed rods have been observed, and which are shown in Fig.3. The microstructures exhibit ribbon-like grains in the upsetting zone (zone I), as shown in Fig.3a, which indicates that the degree of deformation is very small in the center and heterogeneous deformation has taken place.

Uniformity of microstructures shown in Fig.3b is promoted in sizing zone II,which indicate large deformation has occurred.As the plastic deformation continues in the first shearing zone III, the widths of the coarse microstructures become narrow, and a large percentage of fined grains appear in Fig.3c,which demonstrates that dynamic recrystallization (DRX) has taken place.Lamellar microstructures in first shearing zone begin to reduce for the large shear strain caused by shear deformation, and the deformed grains begin to turn into recrystallized grains partialy.

In the second shear zone IV, DRX occurs almost completely, but there still exits a small amount of fine-grain strips in the center of the rod shown in Fig.3d. It is noted that the black marks located grain boundaries are overetching positions caused by acetic acid. There are some inherent drawbacks for microstructure due to uneven metal flow. However,the average grain size decreased from about $200 \mu \mathrm{m}$ to about $10 \mu \mathrm{m}$ by using the ES process. The microstructures are not only greatly refined but also relatively uniform because the ES process includes two steps of simple shear,and deformation degree of central part of rods increases, and more DRX occur[10-12]. Therefore, microstructures become smaller and more homogeneous. The similar 
phenomenon of grain refinement is also observed for differential speed rolling on Mg-4.5 $\mathrm{Al}-1.0 \mathrm{Zn}$ alloy and the larger deformation leads to a larger percentage of the DRXed grains[13]. According to the Hall-Petch relationship,the strength and ductility of the sheets could be enhanced as a result of grain refinements. In addition to grain size, homogeneity of the microstructure also has great impact on the mechanical properties of magnesium alloy at room temperature[14].
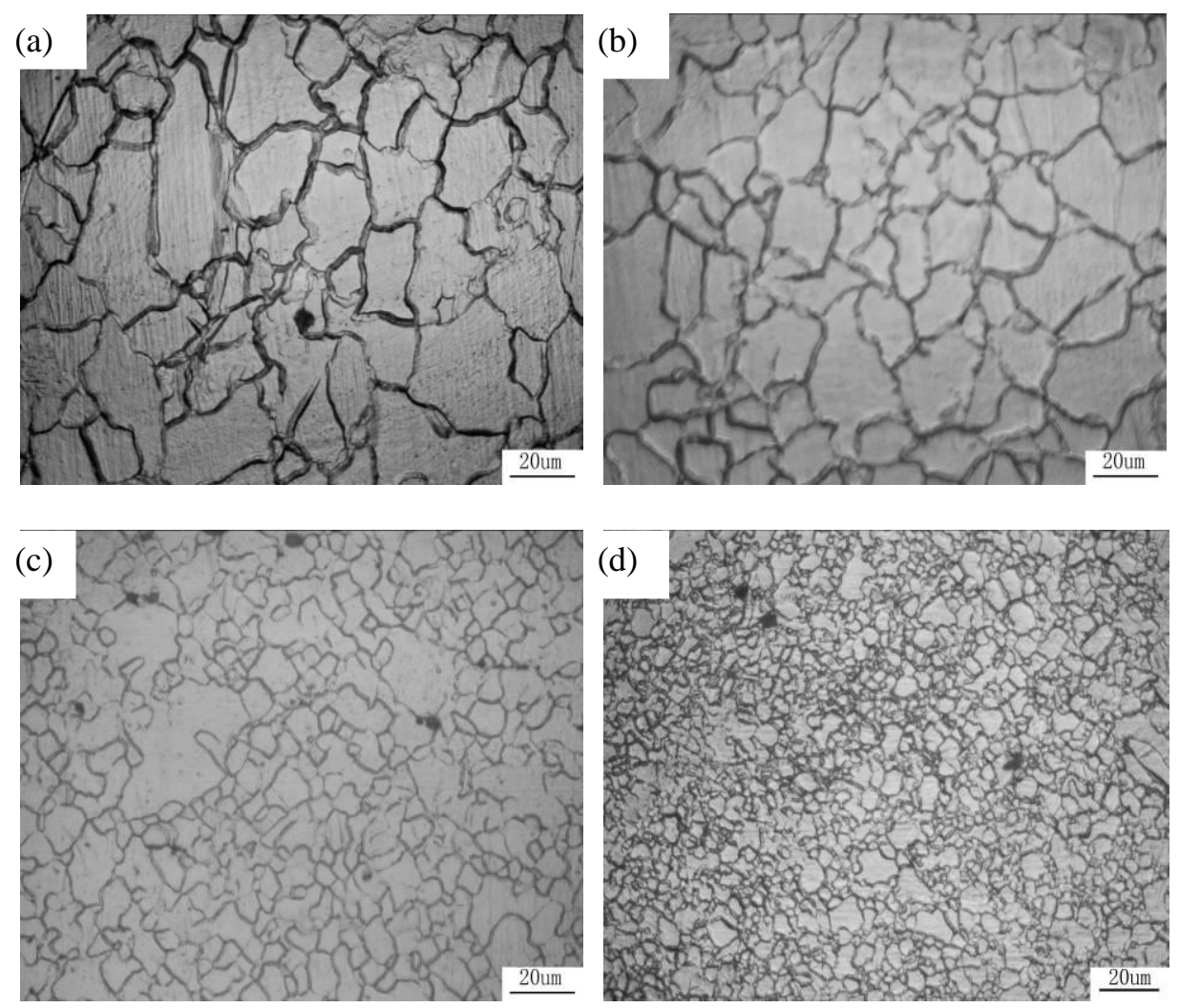

Fig. 3 Microstructural evolution of four zones in the formed rod: (a) upsetting zone I, (b) sizing zone II, (c) the first shearing zone III, (d) the second shearing zone IV. 
In magnesium alloys,strong basal texture is always found, which would result in poor ductility at room temperature[15]. Therefore, it is important to control the grains orientations during the processing. To obtain the orientations of the deformed grains, XRD tests have been carried out. As can be seen from Fig.4, the strongest diffraction peak is the (0002) crystal plane, and (10i1) plane is the second strongest diffraction peak in zone I,zone II. In the upsetting zone I, the strongest diffraction peak is (0002) crystal plane. But in the sizing zone II, the intensities of (1010) and (1011) planes increase obviously. The crystal plane (10i1) is the strongest diffraction peak in the second shear zone, and strength of basal plane (0002) decrease obviously.

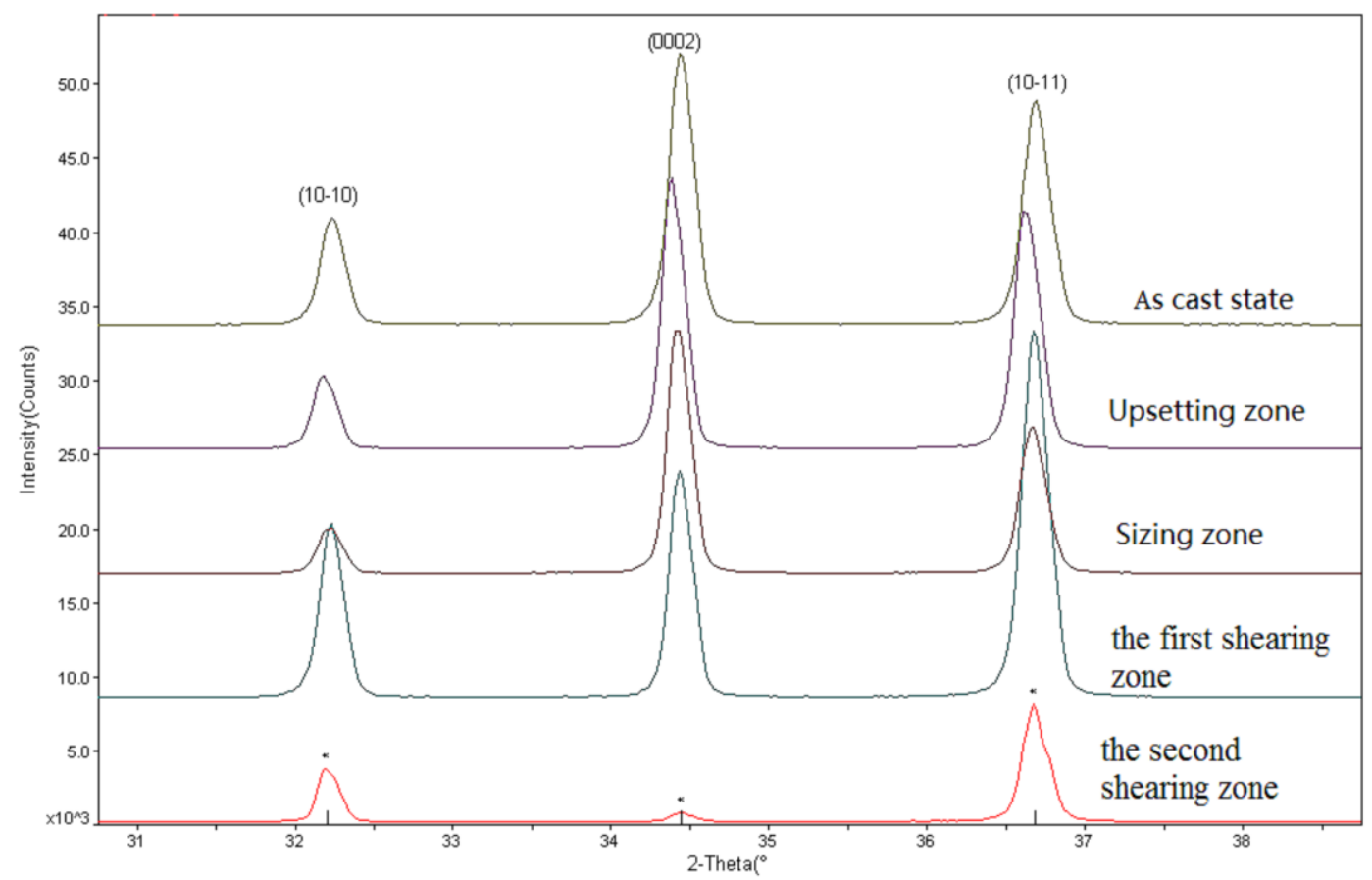

Fig.4. X-Ray diffraction of AZ31 magnesium alloy in different parts of rod in ES die. 
The two shearings would lead to rise of peak intensity ratio,and which shows that the ES process could promote the coexistence of the (0002) basal plane and the non-basal planes. From the XRD test, it could demonstrate that basal texture of (0002) has been weakened greatly and it becomes less dominant after ES process. The weakening of basal texture could be attributed to the shear deformation during the ES process, and which is expected to enhance the formability of magnesium alloys.

Fig.5 presents the grain boundaries maps (SEM-EBSD) of AZ31 magnesium alloy in the sizing zone II and the second shearing zone IV processed by ES process respectively. The low angle grain boundaries (LAGBs) between $1^{\circ}$ and $15^{\circ}$ are marked by thin black lines, and the high angle grain boundaries (HAGBs) over $15^{\circ}$ are labeled by thick black lines, and boundaries with misorientations below $1^{\circ}$ are removed due to the resolution limitations of EBSD.It is clear that microstructures of Fig.5 are consistent with the optical microstructure shown in Fig.3.

There are numerous LAGBs in the AZ31 magnesium alloy for the sizing zone II, as shown in Fig.5a, Many subgrains can be observed inside coarser grains and are elongated in the extrusion direction. The fine grains are gathered together to form band shaped structures.There are a number of large deformed ribbon grains in the sample, and there exist fine recrystallized grains on either side of the coarse ribbon grains. The ribbon grains are probably twin grains. After two shearings, there are no long ribbon grains in the sample, as 
shown in grain boundary maps in Fig.5b. It seems that the LAGBs have evolved into HAGBs, and more finer grains appear. Ribbon grains shown in Fig.5a have changed into fine equiaxed grains. With the increase of accumulated strains caused by successive two shearings, the fraction of grain boundaries increases, and distribution of fine equiaxed grains is more homogeneous.There exist many small uniform recrystallized grains. Therefore, the recrystallization mechanism in the ES process is a continuous dynamic recrystallization.Some coarse grains are surrounded by new fine grains and some fine grains are extended inside the coarser grains.

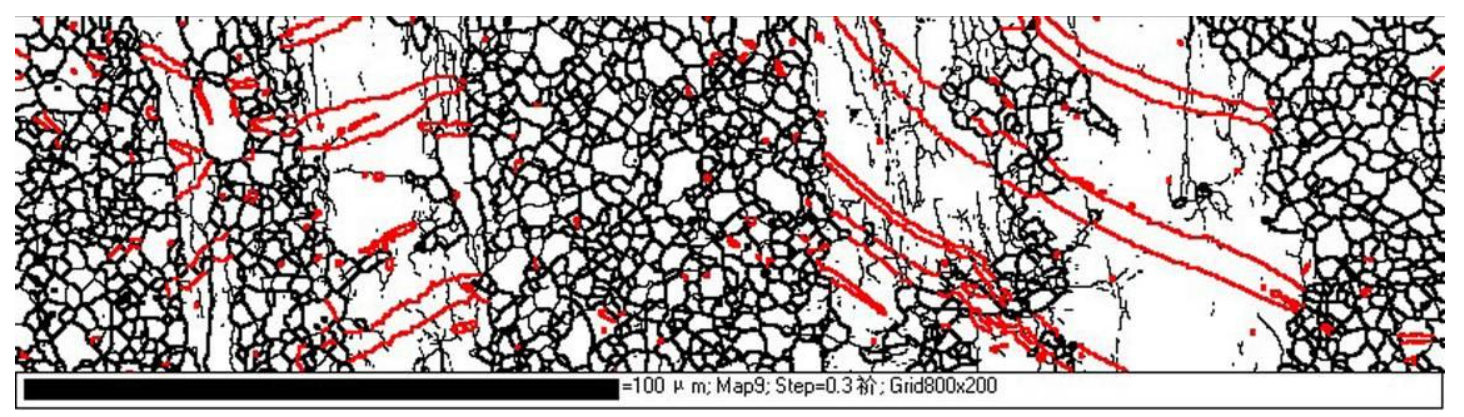

(a)

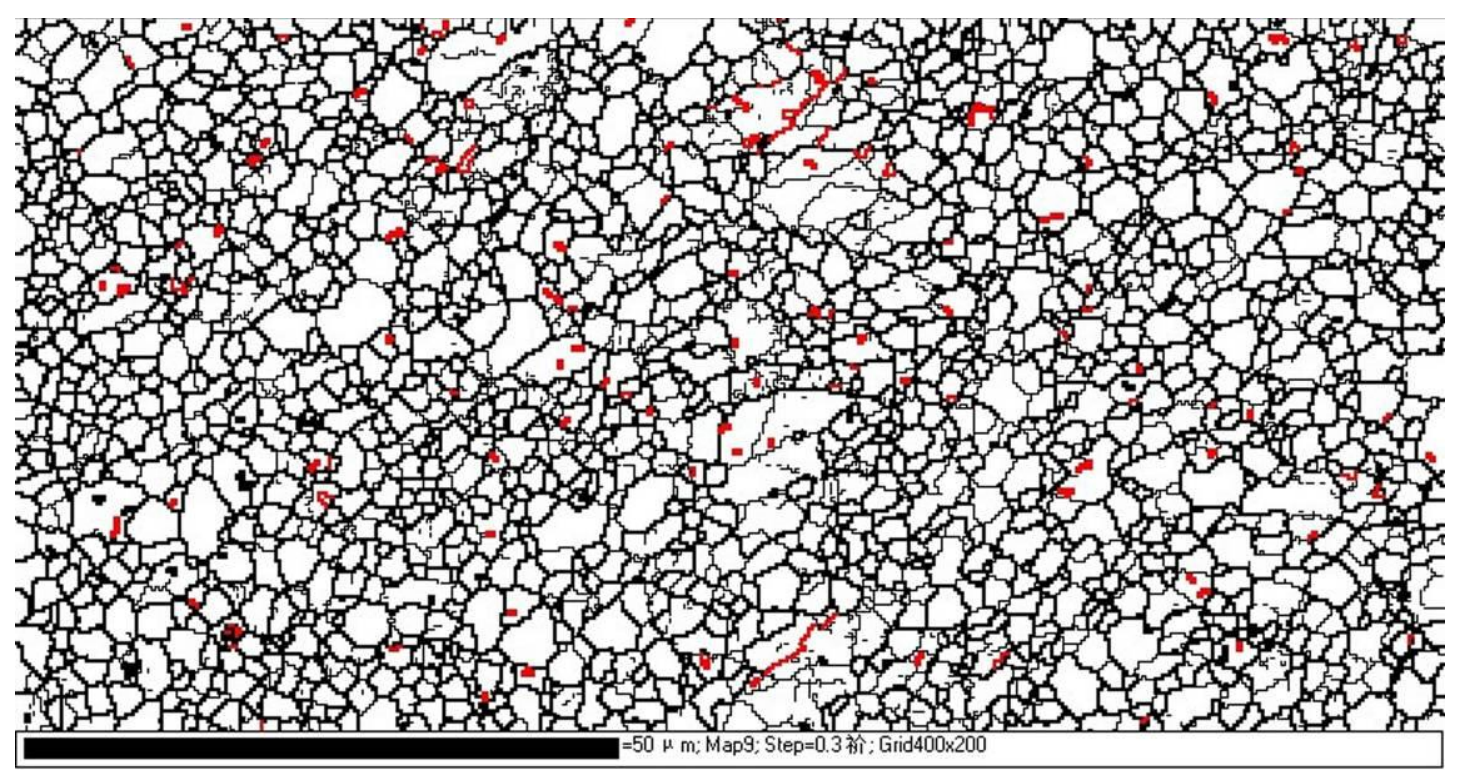


Fig. 5. Grain boundary maps (SEM-EBSD) of AZ31 magnesium alloy processed by ES process in different zones: (a) the sizing zone II ,(b) the second shearing zone IV.

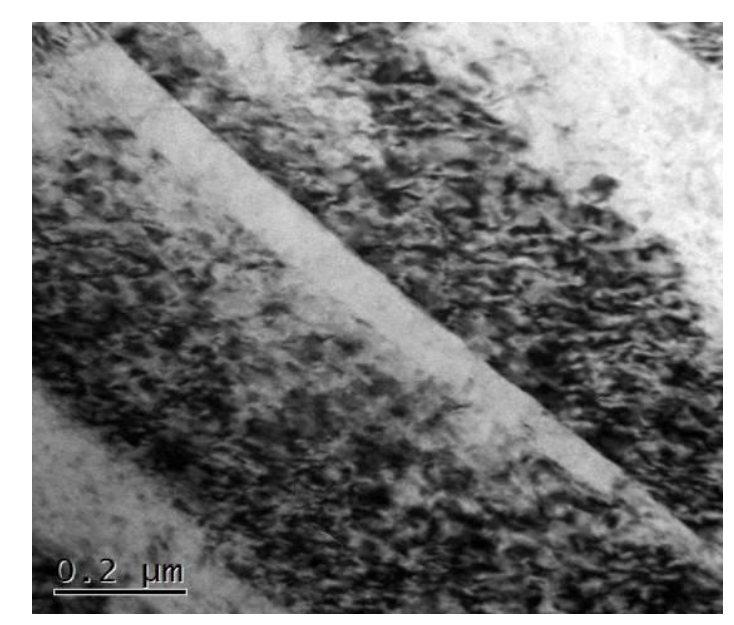

Fig.6. TEM micrographs of magnesium alloy fabricated by ES process.

A typical deformed microstructures after ES process in the TEM image are shown in Fig.6. Parallel twins with narrow deformation bands whose width is about $100-300 \mathrm{~nm}$ on average. Very fine particles have been also found in sample.Unlike in the initial state of magnesium alloy, It is clear that microstructures fabricated by ES process are inhomogeneous.New grains can be produced dynamic recrystallization and nucleation by bulging and subgrain rotation, and dynamic recrystallization behaviors of magnesium alloys is coordinated with formations of secondary phases and twinning. Twinning deformation plays key role in the deformation coordination of ES process.

The principle of ES process is to introduce compressive and accumulated shear strains into the magnesium alloy[7,15,16] .The characters of ES process are that the sample is subjected to variable shear stress via direct extrusion and two deformation shearing steps. The accumulative strains of ES process can be 
expressed as equations (1) which include two parts accumulative strains of direct extrusion and two steps ECAE.

$$
\varepsilon=\ln \lambda+2\left[\frac{2 \cot \left(\frac{\phi}{2}+\frac{\psi}{2}\right)+\psi \csc \left(\frac{\phi}{2}+\frac{\psi}{2}\right)}{\sqrt{3}}\right]
$$

where $\varepsilon$ is the accumulative strain, $\lambda$ the extrusion ratio, $\Phi$ the inner corner angle, and $\Psi$ the outer corner angle. The temperature corrected strain rate $\mathrm{Z}$ is given by equation (2).

$$
Z=\dot{\varepsilon} \exp \left(\frac{Q}{R T}\right)
$$

where $\dot{\varepsilon}$ is strain rate, $\mathrm{Q}$ the activation energy for the deformation, $\mathrm{T}$ the temperature, and $\mathrm{R}$ the gas constant. The Zener-Hollomon parameter $(\mathrm{Z})$ of first direct extrusion is equals to $Z_{1}, v_{1}$ the extrusion speed, $\lambda$ the extrusion ratio, and $\mathrm{R}_{1}$ the billet radius.

$$
\begin{gathered}
Z_{1}=\frac{3 v_{1}}{R_{1}} \ln \lambda \exp \left(\frac{Q}{R T}\right) \\
Z_{2}=\left[\frac{2 \cot \left(\frac{\phi}{2}+\frac{\psi}{2}\right)+\psi \csc \left(\frac{\phi}{2}+\frac{\psi}{2}\right)}{\sqrt{6}}\right] \frac{\sqrt{v_{2}}}{\psi R_{2}} \exp \left(\frac{Q}{R T}\right)
\end{gathered}
$$

And the $\mathrm{Z}$ parameter of second zone for shearing is $\mathrm{Z}_{2}$, where inner corner angle $(\Phi), \psi$ outer corner angle, $\mathrm{v}_{1}$ the speed of extruded rods, $\mathrm{R}_{2}$ radius of extruded rod. The equation (1) includes two parts, the former is the extrusion strain and the later is the strain for ECAE. In this paper, the values of $\lambda, \Phi$, and $\Psi$ are $32.1,120^{\circ}$, and $20^{\circ}$, respectively. Theory Calculation results for strains 
and strain rates and Zener-Hollomon parameters during the three stages of ES process have been shown in Table 2. So large strains occurred during the ES process refine grains.

Table 2. Theory calculation results for dynamic recrystallization.

\begin{tabular}{lllllllll}
\hline$\varepsilon_{1}$ & $\varepsilon_{2}$ & $\varepsilon_{3}$ & $\bar{\varepsilon}_{1}$ & $\bar{\varepsilon}_{2}$ & $\bar{\varepsilon}_{3}$ & $\mathrm{Z}_{1}$ & $\mathrm{Z}_{2}$ & $\mathrm{Z}_{3}$ \\
& & & & & & & & \\
\hline 3.47 & 4.12 & 4.8 & 2.45 & 1.51 & 1.51 & 2.5 & 1.33 & 1.33 \\
\hline
\end{tabular}

The relationship between the average recrystallization grain size (d) and the Zener-Hollomon parameter during dynamic recrystallization is given by equation (5)[14].

$$
-\operatorname{lnd}=\mathrm{A}+\mathrm{B} \ln \mathrm{Z}
$$

where $\mathrm{d}$ is diameter of grain size, $\mathrm{A}$ and $\mathrm{B}$ are constants, and $\mathrm{Z}$ is the Zener-Hollomon parameter.

It can be seen from the equation (3) and (4) and (5) that the process parameters and structure parameters of ES dies have significant impacts on the dynamic recrystallizations of fined grains. So the sizes and volume fraction of dynamic recrystallizations of fined grains are inversely proportional to the accumulation strains. It is obvious that average sizes of grains for high strains are finer than those of low strains. It can be observed that the high strains could refine grains.

\subsection{Hardnesses of magnesium alloy prepared by ES process}

ES process includes direct extrusion and two successive shearing deformations. This new process could improve the work hardening and dynamic 
recrystallization of deformation materials, and microhardness would be changed greatly.Effects of average grain sizes on hardnesses are shown in equation (6)[15].

$$
H_{v}=H_{0}+k^{-} d^{\prime}
$$

where $H_{v}$ is room temperature hardness, $d$ the average grain size, $H_{0}$ the average hardness of the cross section of the ES-prepared rods, $k$ the strengthening coefficient.

The four positions in Fig.1 are researched positions of hardness tests. Hardnesses of different positions for longitudinal sections in rods fabricated by ES process with billet temperature $420^{\circ} \mathrm{C}$ and $450^{\circ} \mathrm{C}$ respectively have been shown in Fig.7 and Fig.8. For deformation of longitudinal section in specimen edge is the most intense, and deformation extent decrease from border to center, hardness distribution of ES-processed specimen is uneven along longitudinal section. Hardnesses of the second shearing zone decrease when extrusion temperature is $450^{\circ} \mathrm{C}$ by comparing with those caused by ES process with extrusion temperature $420^{\circ} \mathrm{C}$, for grains grow up abnormally with higher billet temperature. As the temperature increase, dislocation densities are enhanced and dislocation tangles decrease. If extrusion temperatures are high,grains would grow rapidly, the reductions of grain boundaries would result in decrease of hardness.

Micro-hardness in longitudinal sections of rods vary with different grain sizes shown in Table 3. It is obvious that relationships between micro hardness for extrusion temperature $420^{\circ} \mathrm{C}$ and grain size are consistent with Hall-Petch 
laws [16]. But there exits inverse Hall-Petch rules for extrusion temperature $450{ }^{\circ} \mathrm{C}$, the main reason is that hard and brittle second phases gather in the center of rods when billet temperature of ES process is $450{ }^{\circ} \mathrm{C}$

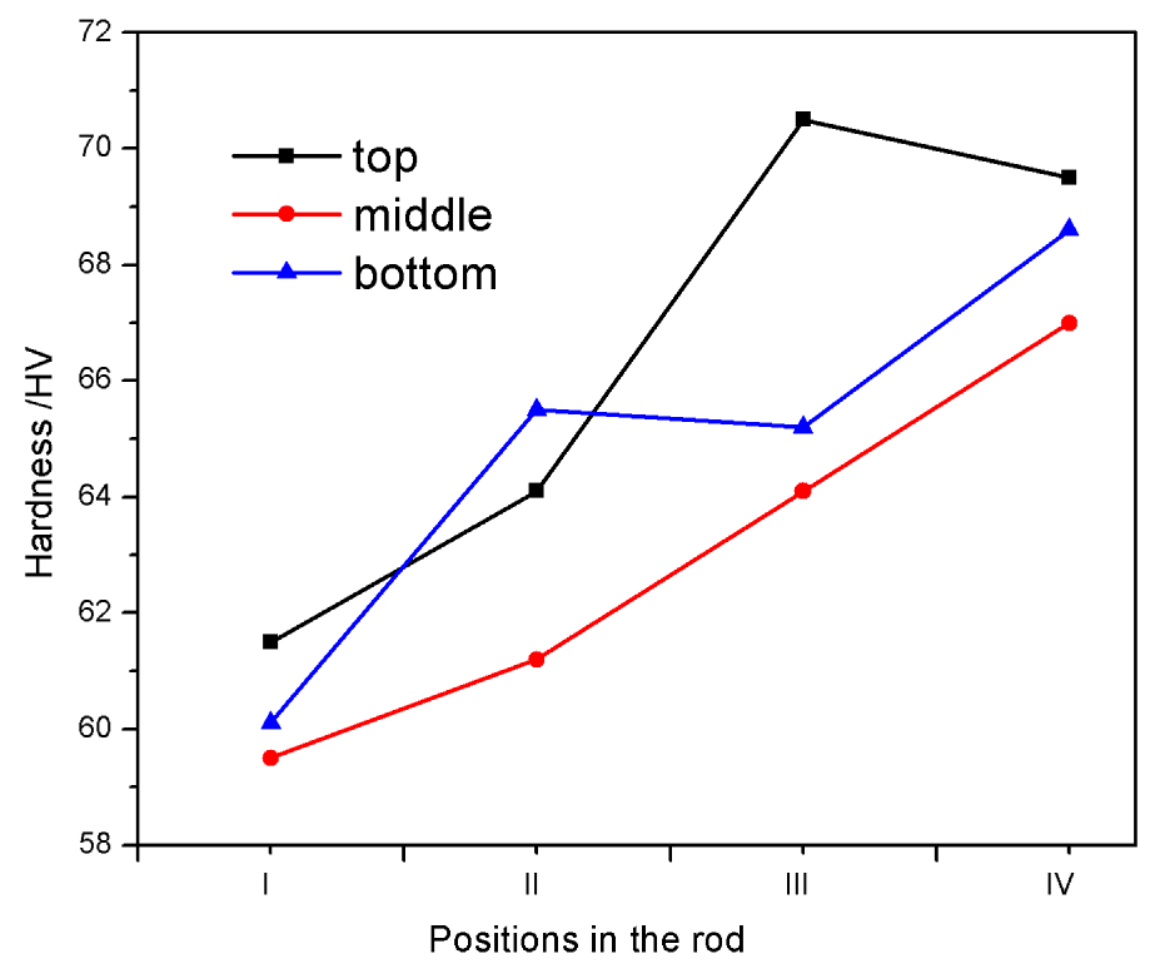

Fig.7 Microhardness for longitudinal section of ES-prepared samples with billet tempreature $420^{\circ} \mathrm{C}$ (error range $\pm 1 \mathrm{HV}$ ). 


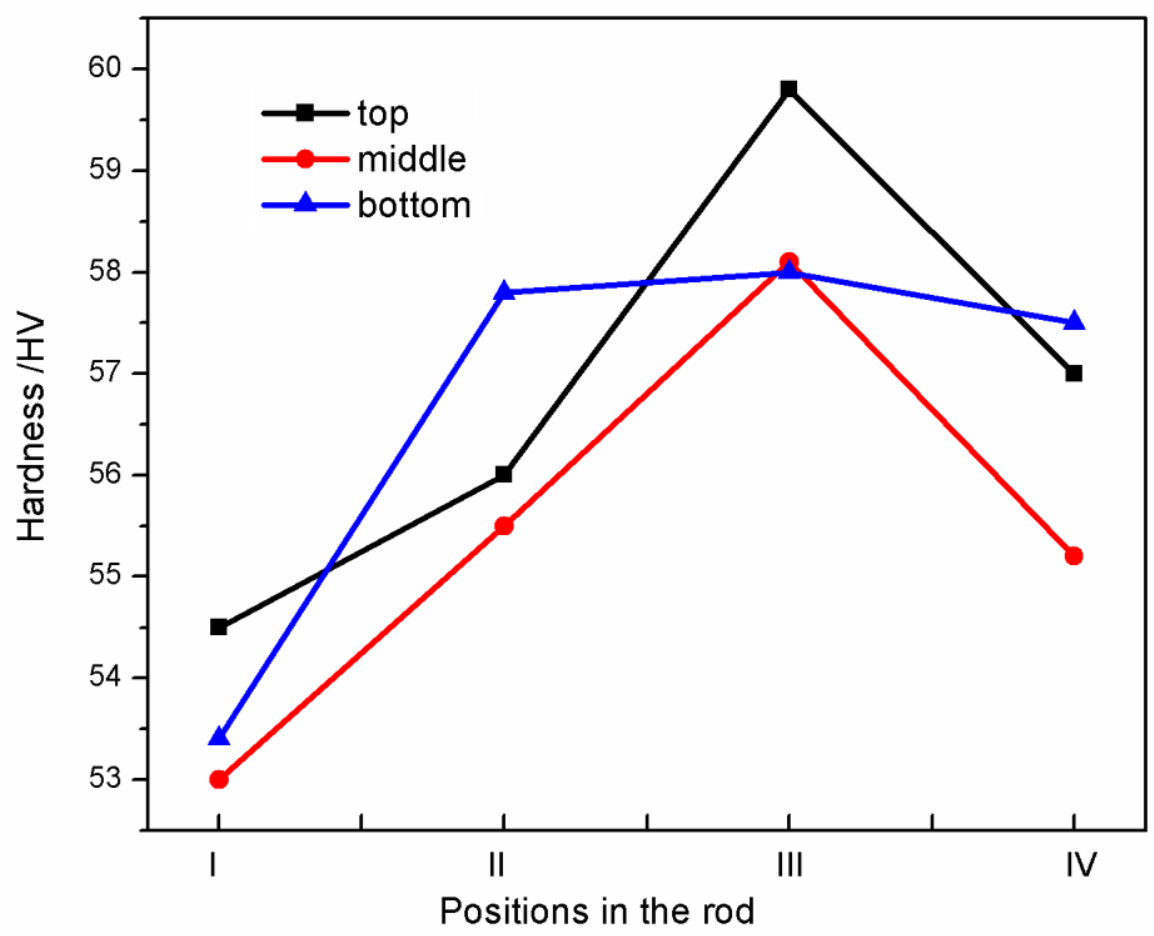

Fig.8 Microhardness for longitudinal section of ES-prepared samples with billet tempreature $450^{\circ} \mathrm{C}($ error range $\pm 1 \mathrm{HV})$.

Table 3 Average grain sizes and hardnesses for different parts in second shearing zone.

\begin{tabular}{llll}
\hline \multicolumn{2}{c}{$420^{\circ} \mathrm{C}$} & \multicolumn{2}{c}{$450^{\circ} \mathrm{C}$} \\
\hline averge grain size & hardness & averge grain size & Hardness \\
$2 \mu \mathrm{m}$ & 69.46 & $6.5 \mu \mathrm{m}$ & 55.03 \\
$5 \mu \mathrm{m}$ & 66.43 & $10 \mu \mathrm{m}$ & 57.52 \\
$2 \mu \mathrm{m}$ & 66.86 & $6.5 \mu \mathrm{m}$ & 56.195 \\
$k=6.92 ; H_{0}=63.32$ & & $K=-27.25 ; H_{0}=66.24$ \\
\hline
\end{tabular}




\subsection{Compression analysis}

Fig.9 shows compressive stress-strain curves for the ES process with different temperatures in different parts of AZ31 magnesium alloy at room temperature. The tensile compression performance has been list in Table 4. It can be seen that yield strengthes and compressive strengthes in sizing zone with extrusion temperature $420^{\circ} \mathrm{C}$ are smaller than those of the second shearing zone. This is because there exits coarse grains in compressive zone I. But changes of strengthes are very little in two zones for difference of grains sizes is very small when extrusion temperature is $450{ }^{\circ} \mathrm{C}$.

Table 4 Compression properties in different parts and temperature.

\begin{tabular}{|c|c|c|c|c|}
\hline & $\begin{array}{c}420^{\circ} \mathrm{C}- \\
\text { Sizing zone }\end{array}$ & $\begin{array}{c}420^{\circ} \mathrm{C}- \\
\text { Second } \\
\text { Shearing } \\
\text { zone }\end{array}$ & $\begin{array}{l}450^{\circ} \mathrm{C}- \\
\text { Sizing } \\
\text { zone }\end{array}$ & $\begin{array}{c}450^{\circ} \mathrm{C}- \\
\text { Second } \\
\text { Shearing } \\
\text { zone }\end{array}$ \\
\hline $\begin{array}{l}\text { yield strength } \\
\qquad \sigma_{0.2}(\mathrm{MPa})\end{array}$ & 85 & 168 & 97 & 70 \\
\hline $\begin{array}{l}\text { Iensile strength } \\
\text { (MPa) }\end{array}$ & 368 & 471 & 325 & 401 \\
\hline
\end{tabular}




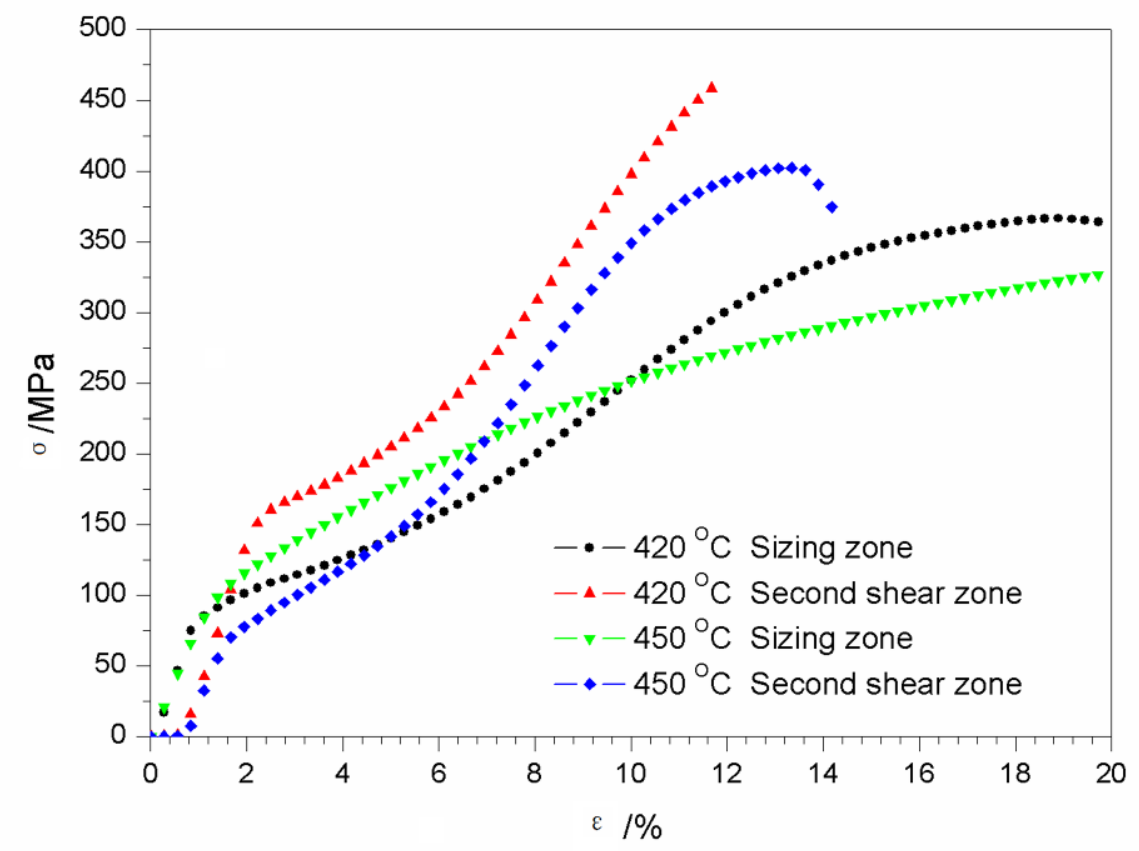

Fig.9 Tensile stress vs. strain curves in sizing zone II and second shear zone

IV at room temperature of AZ31 ES-prepared with different temperatures.

The relationship between strain rate and yield stress usually is shown in the formula (7)[17-19].

$$
\sigma_{s}=\sigma_{0}\left(\frac{\dot{\varepsilon}}{\dot{\varepsilon}}\right)^{n}
$$

Where $\sigma_{\mathrm{s}}$ and $\sigma_{0}$ are the strain rate and yield stress respectively. $\mathrm{n}$ is a constant and less than 1 .

Mechanical properties of AZ31 magnesium alloy should be associated with strain rates. Schmid factor of basal plane increase after ES process. The axial tensile deformation due to basal slip is easy to be moved,and which may decrease yield strength. Slips distance of dislocation become shorter after the grains are refined. Stress concentration near the grain boundaries would be 
released through the non basal slip, grain boundary sliding and dynamic recovery process.

\subsection{Tensile properties}

Stress-strain curves at room temperature tensile tests are shown in Fig.10. From the curves, strength and elongation of prepared sample increase with dropping of temperature. ES process can improve the compression performance of magnesium alloy to a certain extent, at the same time increase the yield strength and tensile strength. Grains can be refined, and the elongation is $12 \%$, $\sigma_{\mathrm{b}}$ is $280 \mathrm{MPa}$ for ES-prepared magnesium alloy. Local compression stresses are exerted on billets for mulitple directions during ES process. So the physical properties of metal and mechanical state are formed homogeneously, plasticity would be increased.

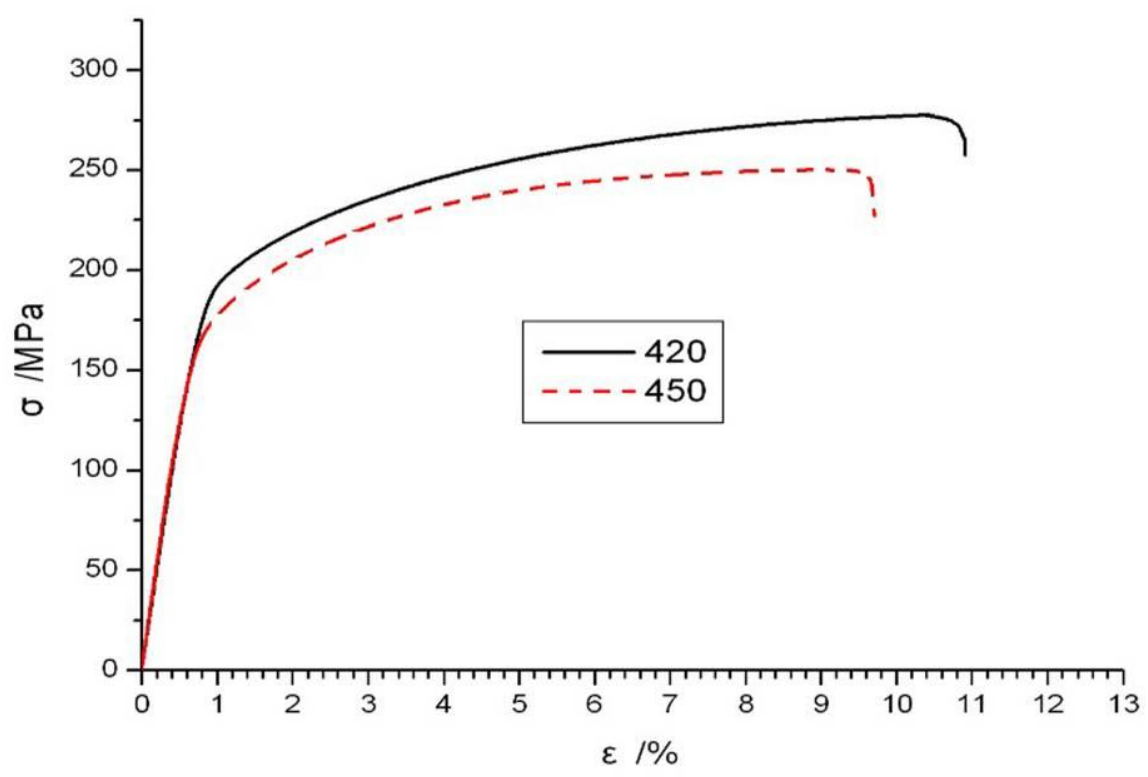

Fig.10 Curves of tensile stress and strain at room temperature of ES-prepared AZ31 with different temperatures 


\subsection{The asymmetry between tension and compression}

Magnesium alloys have a hexagonal close-packed (hcp) crystal structure and hence a limited number of easy-to activate independent slip systems[20-23]. Due to the strong dependence of deformation mechanisms on crystal orientation, it can be expected that prepared samples with deformation texture will exhibit pronounced plastic anisotropy and tension-compression asymmetry in subsequent mechanical testing.There exist significant differences of tensile yield strength and compressive yield strength for wrought magnesium alloys. The compressive yield strengths are significantly lower than the tensile yield strength, which is called the tension compression asymmetry.The tension-compression performances with different temperatures are shown in Table 5. It is obvious that compressive yield strength of wrought magnesium alloy is lower than the tensile yield strength, and the ratio is $0.5-0.7$. For direct extrusion of magnesium alloy, compression yield strength is generally lower than $1 / 2$ of the axial tensile yield strength.The asymmetries of tensile and compressive strength for magnesium alloys restrict their application. Compressive yield strength is lower than the tensile yield strength for ES process. The ratio is 0.85 when extrusion temperature is $420{ }^{\circ} \mathrm{C}$, and the ratio is 0.41 when extrusion temperature is $450^{\circ} \mathrm{C}$.

For the quantitative description of the intensities difference, spitzig and richmond defined the parameters of intensity difference SDE (shorten for strength differential effect), and the calculation formula is shown in equation (7) 
[24-26]. As can be seen the SDE values from Table 5, the lower temperature can effectively reduce the differences of yield strength and tension.

$$
S D E=2 \frac{\sigma_{c}-\sigma_{t}}{\sigma_{c}+\sigma_{t}}
$$

Where $\sigma_{\mathrm{c}}(\mathrm{MPa})$ and $\sigma_{\mathrm{t}}(\mathrm{MPa})$ are uniaxial compressive and tensile yield strength respectively.

Table 5 Tensile and compression properties at different temperatures

\begin{tabular}{|c|c|c|c|c|}
\hline & $\begin{array}{l}\text { Compression } \\
\left(420^{\circ} \mathrm{C}\right)\end{array}$ & $\begin{array}{l}\text { Tensile } \\
\left(420^{\circ} \mathrm{C}\right)\end{array}$ & $\begin{array}{l}\text { Compression } \\
\left(450^{\circ} \mathrm{C}\right)\end{array}$ & $\begin{array}{l}\text { Tensile } \\
\left(450^{\circ} \mathrm{C}\right)\end{array}$ \\
\hline $\begin{array}{l}\text { Yield strength } \\
\sigma_{0.2}(\mathrm{MPa})\end{array}$ & 168 & 196 & 70 & 170 \\
\hline Compressive & & & & \\
\hline $\begin{array}{l}\text { tensile strength } \\
(\mathrm{MPa})\end{array}$ & 471 & 275 & 401 & 240 \\
\hline $\mathrm{SDE}$ & & 0.15 & & 0.83 \\
\hline Compression & & & & \\
\hline $\begin{array}{l}\text { elongation } \\
\text { rate }(\%)\end{array}$ & 12 & 10.9 & 13.5 & 9.6 \\
\hline
\end{tabular}

\section{Conclusions}

(1)The ES die with two shearings has been designed and manufactured. ES process experiments have been conducted with the speed of $0.5 \mathrm{~m} / \mathrm{min}$ and extrusion ratio 32.1 and temperature $420{ }^{\circ} \mathrm{C}$ and $450^{\circ} \mathrm{C}$ respectively. 
(2)Metallographic analyses of optical microscopies show that the ES process could improve dynamic recrystallization during ES process.Microstructures becomes more uniform and finer by comparing to the original as-cast condition owing to the two shearings of ES process. The macro-texture analyses based on X-ray diffraction method show that ES process could weaken the basal texture of (0002). The micro-texture analyses of EBSD show that ES process would decrease intensities of basal textures.

(3) Vickers hardness tests and compression and tensile tests for different positions of ES-prepared samples with different extrusion temperatures have been tested.ES process with low extrusion temperature would improve grain refinements and yield strength, tensile strength and hardness or strength.There exits strong asymmetry for tension compression in ES-prepared magnesium alloy rods.

\section{Acknowledgements}

This research is funded by Chongqing Research Program of Basic Research and Frontier Technology(cstc2015jcyjBX0054),National Science Foundation of China(51101176),China Postdoctoral Science Foundation funded project(2015T81087 and 2014M552575).

\section{References}

[1]H.R. Song, Y.S. Kim, W.J. Nam, Metal,Mater.Inter.12(2006)7-12.

[2]Lee,S.C.,Ha,S.Y.,Kim, K.T., Hwang,S.M.,Huh, L.M.,Chung,H.S., Mater.Sci.Eng.A.371(2004) 306-312.

[3]Somjeet Biswas,Benoît Beausir,Laszlo S.Toth, atyam Suwas, 
Acta Materialia.61(2013)5263-5277.

[4] Chen, Q., Zhao, Z., Chen, G., \& Wang, B.,Journal of Alloys

\&Compounds.632(2015)190-200.

[5]K.Matsuyama,Y.Miyahara,Z.Horita,T.G.Langdon,Acta

Materialia.51(2003)3073-3084.

[6]Kiyoshi Matsubara,Yuichi Miyahara,Zenji Horita,Terence G.

Langdon,Metallurgical and Materials Transactions A.35(2004)1734-1744.

[7]Dmitry Orlov,George Raab, Torbjorn T,Lamark, Mikhail Popov ,uri Estrin,Acta

Materialia.59(2011)375-385.

[8]QingshanYang,BinJiang,GuanyuZhou,JiahongDai,FushengPan,

Mater.Sci.Eng.A.590(2014)440-447.

[9]Gong X.,Li H.,Kang S.B.,Cho J.H.,and Li S,Materials and

Design.31(2010)1581-1587.

[10]Xia,X.,Chen,Q.,Zhao,Z.,Ma,M.,Li,X.,\&Zhang,K.,Journal of Alloys \&Compounds.623(2015)62-68.

[11]Chen,Q.,Yuan,B.,Lin,J.,Xia,X.,Zhao,Z.,\&Shu,D.,Journal of Alloys\& Compounds.584(2014)63-75.

[12]Gong, X., Li, H., Kang, S. B., Cho, J. H., \& Li, S., mater des. $31(2010) 1581-1587$.

[13]Chen,Q., Shu,D.,Hu,C.,Zhao,Z.,\&Yuan,B., Mater.Sci.Eng.A.541(2012)98-104.

[14]Yu Sirong, Li Dongcheng, N. Kim, Mater. Sci. Eng. A 420 (2006)165-170.

[15]Chen,Q.,Yuan,B.,Zhao,G.,Shu,D.,Hu,C.,\&Zhao,Z.,et al.,Mater.Sci.Eng.A. 
537(2012)25-38.

[16] Q.D.Qin,Y.G.Zhao,P.J.Cong,W.Zhou,B.Xu, Mater.Sci.Eng.A.444 (2007)99-103.

[17]Chen,Q.,Zhao, Z.,Zhao,Z.,Hu,C., \& Shu,D,Journal of Alloys\&Compounds, 509(2011)7303-7315.

[18]Ramin Jahadi,Mohammad Sedighi,Hamid Jahed,Mater.Sci.Eng.A.

593(2014)178-184.

[19]Chen,Y.J.,Wang,Q.D.,Roven,H.J.,Karlsen,M.,Yu,Y.D.,\&Liu,M.P.,et al., Journal of Alloys \& Compounds. 462(2008)192-200.

[20] Yu,D.,Zhang,D.,Sun,J.,Luo,Y.,Xu, J.,\& Zhang,H.,et al., Journal of Alloys and Compounds.690 (2016)553-560.

[21]Kim, S. H., You, B. S., \& Park, S. H.,Journal of Alloys and Compounds. 690(2017)417-423.

[22]Gui, Z., Kang, Z., \& Li, Y.,Journal of Alloys \& Compounds.685(2016)222-230.

[23]Park, S. H., Kim, S. H., Kim, H. S., Yoon, J., \& You, B. S., Journal of Alloys \& Compounds. 667(2016)170-177.

[24]Li,C.J., Sun,H. F.,Li,X.W., Zhang, J. L., Fang, W.B., \& Tan, Z.Y.,Journal of Alloys \& Compounds.652 (2015)122-131.

[25]Lin, C.Y.,Tsai, H. J., Chao,C.G., \& Liu,T.F., Journal of Alloys \& Compounds.530 (2012)48-55.

[26]Tahreen,N.,Zhang,D.F.,Pan, F. S., Jiang, X. Q., Li, D. Y., \& Chen, D. L. , Journal of Alloys and Compounds.688(2016)270-284. 


\section{List of Figure captions}

Fig.1.Schematic diagram of ES die with channel angle $120^{\circ}$ and some parts chosen to be researched:I-upsetting zone, II- sizing zone, III-the first shearing zone, IV-the second shearing zone.

Fig.2.The original microstructures for as cast AZ31 magnesium alloy.

Fig. 3 Microstructural evolution of four zones in the formed rod: (a) upsetting zone I,

(b) sizing zone II, (c) the first shearing zone III, (d) the second shearing zone IV.

Fig.4.X-Ray diffraction of AZ31 magnesium alloy in different parts of rod in ES die.

Fig.5. Grain boundary maps (SEM-EBSD) of AZ31 magnesium alloy processed by ES process in different zones: (a) the sizing zone II ,(b) the second shearing zone IV.

Fig.6.TEM micrographs of magnesium alloy fabricated by ES process.

Fig.7 Microhardness for longitudinal section of ES-prepared samples with billet tempreature $420^{\circ} \mathrm{C}$ (error range $\pm 1 \mathrm{HV}$ ).

Fig.8 Microhardness for longitudinal section of ES-prepared samples with billet tempreature $450^{\circ} \mathrm{C}$ (error range $\pm 1 \mathrm{HV}$ ). 
Fig.9 Tensile stress vs. strain curves in sizing zone II and second shear zone IV at room temperature of AZ31 ES-prepared with different temperatures.

Fig.10 Curves of tensile stress and strain at room temperature of ES-prepared AZ31 with different temperatures

\section{List of Table Captions}

Table 1. Process parameters of ES process.

Table 2. Theory calculation results for dynamic recrystallization.

Table 3. Average grain sizes and hardnesses for different parts in second shearing zone.

Table 4. Compression properties in different parts and temperature.

Table 5.Tensile and compression properties at different temperature 
Table 1 process parameters of ES process

\begin{tabular}{lccc}
\hline billet temperature & die & container & Extrusion \\
& temperature & temperature & speed \\
\hline $420^{\circ} \mathrm{C}$ & $400^{\circ} \mathrm{C}$ & $400^{\circ} \mathrm{C}$ & $0.5 \mathrm{~m} / \mathrm{min}$ \\
$450^{\circ} \mathrm{C}$ & $430^{\circ} \mathrm{C}$ & $430^{\circ} \mathrm{C}$ & $0.5 \mathrm{~m} / \mathrm{min}$ \\
\hline
\end{tabular}


Table 2. Theory calculation results for dynamic recrystallization

\begin{tabular}{ccccccccc}
\hline$\varepsilon_{1}$ & $\varepsilon_{2}$ & $\varepsilon_{3}$ & $\dot{\bar{\varepsilon}}$ & $\dot{\bar{\varepsilon}}$ & $\dot{\bar{\varepsilon}}$ & $\mathrm{Z}_{1}$ & $\mathrm{Z}_{2}$ & $\mathrm{Z}_{3}$ \\
& & & & & & & & \\
\hline 3.3 & 4.1 & 4.6 & 2.6 & 1.4 & 1.4 & 2.1 & 1.12 & 1.12 \\
\hline
\end{tabular}


Table 3 Average grain sizes and hardnesses for different parts in secondary shearing zone

\begin{tabular}{ll|lc}
\hline \multicolumn{2}{c|}{$420^{\circ} \mathrm{C}$} & \multicolumn{2}{|c}{$450^{\circ} \mathrm{C}$} \\
\hline Averge grain size & Hardness & Averge grain size & Hardness \\
$2 \mu \mathrm{m}$ & 69.46 & $6.5 \mu \mathrm{m}$ & 55.03 \\
$5 \mu \mathrm{m}$ & 66.43 & $10 \mu \mathrm{m}$ & 57.52 \\
$2 \mu \mathrm{m}$ & 66.86 & $6.5 \mu \mathrm{m}$ & 56.195 \\
$k=6.92 ; H_{0}=63.32$ & & \multicolumn{2}{|c}{$K=-27.25 ; H_{0}=66.24$} \\
\hline
\end{tabular}


Table 4 Compression properties in different parts and temperature

\begin{tabular}{lcccc} 
& $420^{\circ} \mathrm{C}-$ & $420^{\circ} \mathrm{C}-$ & $450^{\circ} \mathrm{C}-$ & $450^{\circ} \mathrm{C}-$ \\
& Sizing & Second & Sizing & Second \\
& zone & Shearing & zone & Shearing \\
& & zone & & zone \\
& & 168 & 97 & 70 \\
yield strength & 85 & & & \\
$\sigma_{0.2}(\mathrm{MPa})$ & 368 & 471 & 325 & \\
Tensile & & & & \\
$(\mathrm{MPa})$ & & & & \\
\hline
\end{tabular}


Table 5 Tensile and compression properties at different temperature

\begin{tabular}{|c|c|c|c|c|}
\hline & $\begin{array}{l}\text { Compression } \\
\left(420^{\circ} \mathrm{C}\right)\end{array}$ & $\begin{array}{l}\text { Tensile } \\
\left(420^{\circ} \mathrm{C}\right)\end{array}$ & $\begin{array}{l}\text { Compression } \\
\left(450^{\circ} \mathrm{C}\right)\end{array}$ & $\begin{array}{l}\text { Tensile } \\
\left(450^{\circ} \mathrm{C}\right)\end{array}$ \\
\hline \multicolumn{5}{|l|}{ Yield strength } \\
\hline & 168 & 196 & 70 & 170 \\
\hline \multicolumn{5}{|l|}{$\sigma_{0.2}(\mathrm{MPa})$} \\
\hline \multicolumn{5}{|l|}{ Compressive } \\
\hline tensile strength & 471 & 275 & 401 & 240 \\
\hline \multicolumn{5}{|l|}{$(\mathrm{MPa})$} \\
\hline SDE & \multicolumn{2}{|r|}{0.15} & \multicolumn{2}{|r|}{0.83} \\
\hline \multicolumn{5}{|l|}{ Compression } \\
\hline elongation & 12 & 10.9 & 13.5 & 9.6 \\
\hline rate $(\%)$ & & & & \\
\hline
\end{tabular}

